\title{
Giant Ovarian Serous Cystadenoma in an Infant: Report of a Rare Case
}

\author{
Medhavi Vimal $^{1, \odot}$ Priti Chatterjee ${ }^{1}$ Anita Nangia ${ }^{1} \quad$ S. R. Choudhury ${ }^{2}$ \\ ${ }^{1}$ Department of Pathology, Lady Hardinge Medical College, Delhi, \\ India \\ ${ }^{2}$ Department of Paediatric Surgery, Lady Hardinge Medical College, \\ Delhi, India

\begin{abstract}
Address for correspondence Priti Chatterjee, MBBS, MD, Department of Pathology, Lady Hardinge Medical College, Delhi - 110001, India (e-mail: doctorpriti@gmail.com).
\end{abstract}

J Lab Physicians 2021;13:388-390.

\begin{abstract}
Keywords

- cystectomy

- neonatal ovarian cyst

- serous cystadenoma in infant

The incidence of abdominal cysts in infants is 1 in 500 to 1 in 1,000 live births. Among the ovarian cysts in infants, serous cystadenoma is extremely rare with only few reported cases in the literature. Here, we report a case of a giant neonatal ovarian serous cystadenoma treated with laparoscopic cystectomy and confirmed by histopathological examination.

A 27-year-old delivered a female baby with uneventful caesarean section at full term. The antenatal ultrasonography (USG) in third trimester had showed an abdominal cyst in the left side of the abdomen. Postnatal USG was suggestive of omental cyst. A contrast-enhanced computed tomography scan of the neonate showed a large cyst occupying the entire abdomen. On laparoscopic evaluation, a cystic mass filled with $500 \mathrm{~mL}$ of clear yellow fluid was seen in the left pelvic fossa. Left ovary could not be visualized separately. The right ovary, fallopian tubes, and uterus were normal. The entire cyst was removed and sent for histopathological examination. On gross examination, a unilocular cyst measuring $10 \times 8 \times 6.5 \mathrm{~cm}$ with a wall thickness of $0.2 \mathrm{~cm}$ was noted. On microscopic examination, the histomorphological features were consistent with serous cystadenoma of the ovary. There is a paucity of literature regarding pathological diagnosis of such cases and hence we report one such case.
\end{abstract}

\section{Introduction}

The incidence of abdominal cysts in infants is in the range of 1 in 500 to 1 in 1,000 live births. ${ }^{1}$ With the radiological advancement, these cysts can be easily detected on ultrasonography (USG) toward the third trimester of gestation. ${ }^{2}$ Among the ovarian cysts in infants, serous cystadenoma is extremely rare with only few reported cases in the literature. Here, we report a case of a giant neonatal ovarian serous cystadenoma treated with laparoscopic cystectomy and confirmed by histopathological examination.

published online July 14,2021
DOI https://doi.org/

$10.1055 / \mathrm{s}-0041-1732487$ ISSN 0974-2727

\section{Case Report}

A 27-year-old female presented in third trimester and her routine antenatal USG showed presence of an intra-abdominal cyst in the left side of the abdomen of the fetus. The baby was delivered at term through uneventful cesarean section. Postnatal USG at birth showed a large unilocular cyst and a radiological diagnosis of omental cyst was made. Contrast-enhanced computed tomography scan showed a large unilocular cyst measuring $10 \times 8 \times 6 \mathrm{~cm}$ occupying the entire abdomen. The origin of the cyst could not (c) 2021. The Indian Association of Laboratory Physicians.

This is an open access article published by Thieme under the terms of the Creative Commons Attribution-NonDerivative-NonCommercial-License, permitting copying and reproduction so long as the original work is given appropriate credit. Contents may not be used for commercial purposes, or adapted, remixed, transformed or built upon. (https://creativecommons.org/licenses/by-nc-nd/4.0/).

Thieme Medical and Scientific Publishers Pvt. Ltd. A-12, 2nd Floor, Sector 2, Noida-201301 UP, India 
be ascertained ( $\boldsymbol{- F i g . ~ 1 ) . ~ N o ~ d a u g h t e r ~ c y s t s , ~ p a p i l l a r y ~ p r o j e c - ~}$ tions, or solid areas were seen. The baby was taken for a laparoscopic evaluation and a large cystic mass filled with clear fluid was seen in the left pelvic fossa. The left ovary could not be visualized separately. The right ovary, fallopian tube, and uterus were normal. The cyst was drained intraoperatively that yielded $500 \mathrm{~mL}$ of clear fluid following which the entire cyst was removed and sent for histopathological examination. On gross examination, a unilocular, thin-walled cyst measuring $10 \times 8 \times 6.5 \mathrm{~cm}$ with a wall thickness of $0.2 \mathrm{~cm}$ was

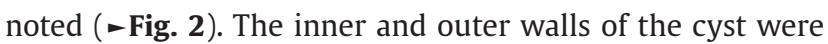
smooth. An occasional tiny papillary projection could be seen arising from the inner wall of the cyst. A small part of normal ovary was seen at the periphery that also had few tiny cysts varying in size from 0.2 to $0.4 \mathrm{~cm}$. On microscopy, the large unilocular cyst was lined by flattened to cuboidal cells. Focal presence of an occasional papillary excrescence was seen. The underlying ovarian stroma was edematous. Sections examined from the periphery showed a few small cysts lined by an inner layer of granulosa cells and outer layer of luteinized cells ( - Fig. $\mathbf{3}$ ). Numerous primordial graafian follicles

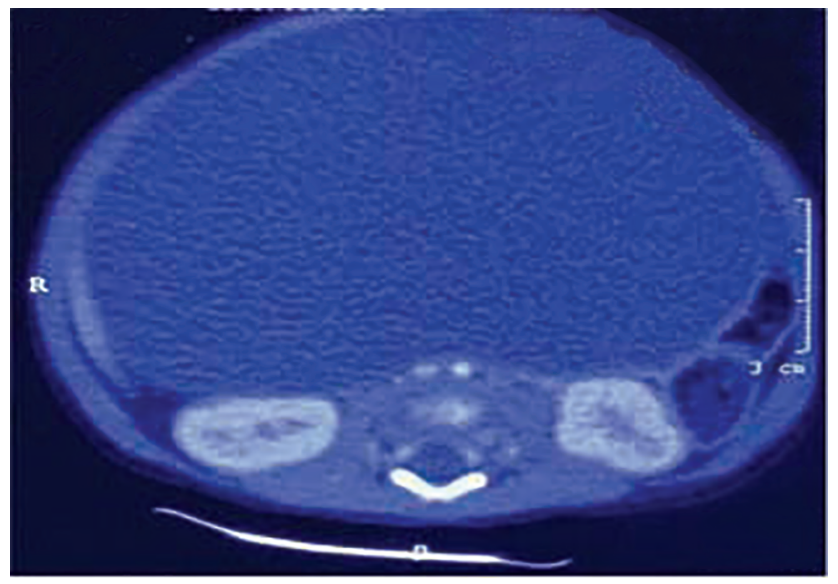

Fig. 1 Contrast-enhanced computed tomography scan showing a giant ovarian cyst.

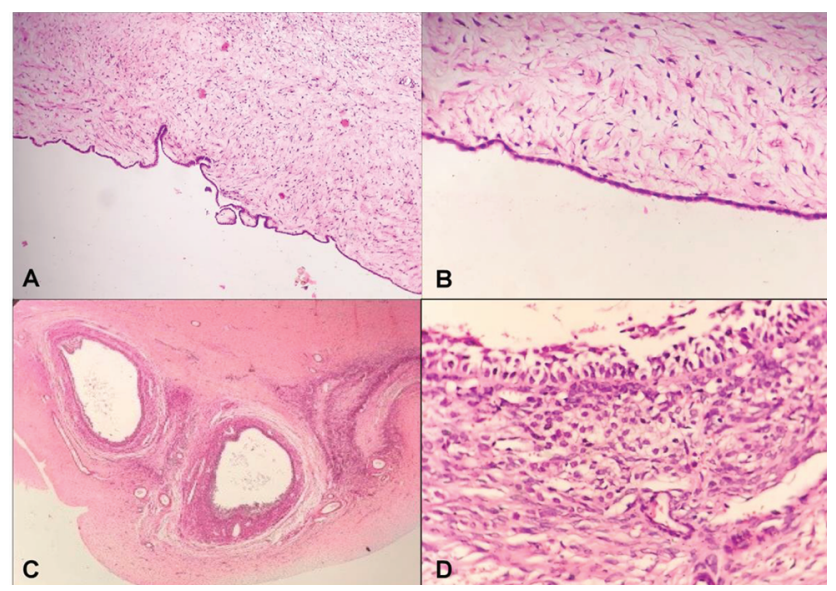

Fig. 3 (A) Cyst wall showing tiny papillary processes Hematoxylin and Eosin (H\&E) 100×. (B) Cyst wall lined by flattened cuboidal epithelium H\&E 400×. (C) Multiple cystic follicles H\&E 100×. (D) Inner lining of granulose cells and outer layer of theca cells in cystic follicles H\&E 400×.

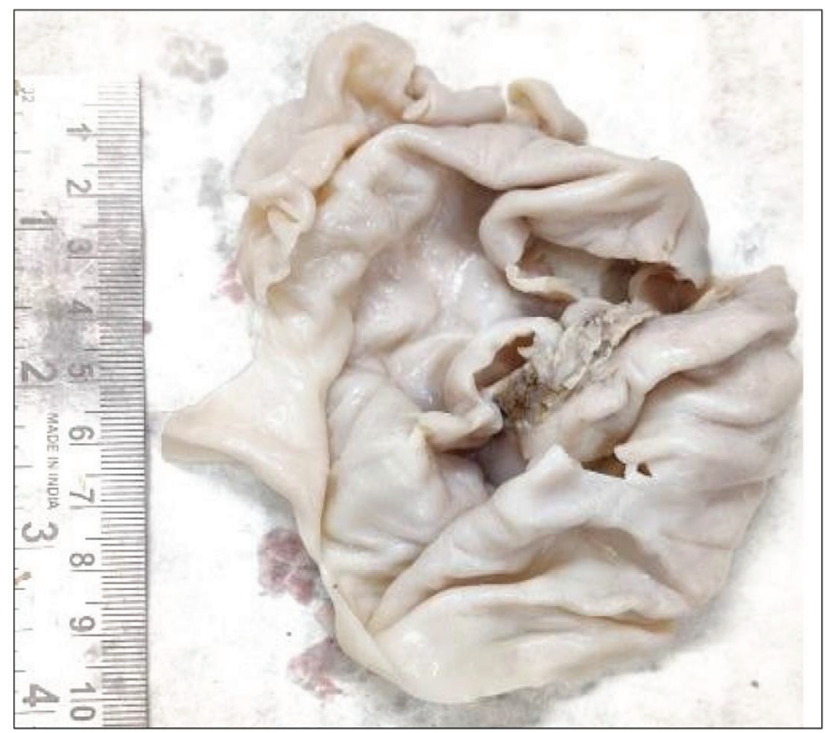

Fig. 2 Unilocular, thin-walled cyst.

were present at the periphery. Based on these findings, a diagnosis of serous cystadenoma with multiple cystic follicles was made. The baby was followed up at 6 weeks and till 6 months thereafter with uneventful postoperative recovery.

\section{Discussion}

The frequency of ovarian cysts is estimated to be 1 in 2,600 pregnancies and is the most common intrabdominal cyst diagnosed in female foetuses. ${ }^{3}$

In newborns, ovarian cysts greater than $2 \mathrm{~cm}$ in diameter are considered pathological. ${ }^{4}$ On radiology, cysts are classified as "small" $(<4 \mathrm{~cm})$ or "large" $(>4 \mathrm{~cm})$, and "simple" or "complex." 5

On histopathological examination, the majority of simple ovarian cysts are follicular or theca lutein cysts. ${ }^{6}$ The ovarian cysts are identified based on their lining epithelium. The most common cyst is follicular ovarian cysts. These cysts are lined by granulosa cells with underlying theca cells and may be surrounded by reticulum. If a cyst is more than $3 \mathrm{~cm}$ in size, then it is regarded as a follicular cyst and as a cystic follicle if it is less than $3 \mathrm{~cm}$ in size. ${ }^{6}$

Serous cystadenomas are uncommon and are generally unilateral, cystic, and unilocular. The cyst is lined by flattened cuboidal or columnar cells with rare or no atypia. Papillary branching may be present but tufting is not present. Calcifications are commonly seen. The underlying ovarian stroma may appear unremarkable. In our case, there was a unilocular cyst lined by cuboidal to flattened cells with underlying edematous ovarian stroma.

On extensive search of the literature, we could find only a few cases reported as ovarian serous cystadenoma in the infants less than 6 months of age. ${ }^{7-9}$ Bhattacharya et al conducted a study on ovarian tumors in pediatric age group. Out of the 151 cases, only three cases were present in the age group of up to 5 years and only one case was diagnosed as serous cystadenoma in the same age group. However, the exact age of the patient with serous cystadenoma was not 
mentioned but was included in the group less than 5 years of age. The baby presented with abdominal lump and cystectomy revealed a unilocular cyst with features suggestive of ovarian serous cystadenoma on histopathology. ${ }^{7}$ Shapiro et al published two case reports on laparoscopic ovarian cystectomy in children. Out of which one case was of a neonate who presented with an abdominal mass and was diagnosed as simple benign ovarian cyst that was confirmed as benign serous cystadenoma on histopathology. ${ }^{8}$ Lee et al published a case report of an ovarian cyst with torsion presenting as a wandering mass in a newborn (7 days) that was diagnosed as serous cystadenoma on histopathology. ${ }^{9}$ In the present case, the cyst was present antenatally; however, the laparoscopic resection was done after birth.

Small cysts generally regress spontaneously; however, larger cysts may undergo complications and hence should be removed surgically in the neonates. The cysts larger than $5 \mathrm{~cm}$ in size tend to undergo complications like torsion and hemorrhage and hence should be removed surgically. Here, we present a case of an ovarian serous cystadenoma in a neonate that was more than $10 \mathrm{~cm}$ in size and hence was managed with laparoscopic surgery.

\section{Conflict of Interest}

None.

\section{References}

1 Chandler JC, Gauderer MW. The neonate with an abdominal mass. Pediatr Clin North Am 2004;51(4):979-997, ix

2 Hasiakos D, Papakonstantinou K, Bacanu AM, Argeitis J, Botsis D, Vitoratos N. Clinical experience of five fetal ovarian cysts: diagnosis and follow-up. Arch Gynecol Obstet 2008;277(6):575-578

3 Trinh TW, Kennedy AM. Fetal ovarian cysts: review of imaging spectrum, differential diagnosis, management, and outcome. Radiographics 2015;35(2):621-635

4 Akın MA, Akın L, Özbek S, et al. Fetal-neonatal ovarian cyststheir monitoring and management: retrospective evaluation of 20 cases and review of the literature. J Clin Res Pediatr Endocrinol 2010;2(1):28-33

5 Aamir M, Punia H, Dalal P, Sharma D. Conservative management of a large neonatal ovarian cyst: a case report. J Clin Diagn Res 2015;9(4):SD04-SD05

6 Jain M, Pujani M, Madan NK, Chadha R, Puri A. Congenital ovarian cyst: a report of two cases. J Lab Physicians 2012;4(1):63-65

7 Bhattacharyya NK, De A, Bera P, Sristidhar M, Chakraborty S, Bandopadhyay R. Ovarian tumors in pediatric age group - a clinicopathologic study of 10 years' cases in West Bengal, India. Indian J Med Paediatr Oncol 2010;31(2):54-57

8 Shapiro EY, Kaye JD, Palmer LS. Laparoscopic ovarian cystectomy in children. Urology 2009;73(3):526-528

9 Lee JH, Tang JR, Wu MZ, Ni YH, Hsu WM. Ovarian cyst with torsion presenting as a wandering mass in a newborn. Acta Paediatr Taiwan 2003;44(5):310-312 